\title{
Pheochromocytoma and paraganglioma: time and space are only part of the essence
}

\author{
Alexander A Leung ${ }^{1,2}$, Janice L Pasieka ${ }^{3}$, Hossein Sadrzadeh ${ }^{4,5}$ and Gregory A Kline ${ }^{1}$ \\ ${ }^{1}$ Division of Endocrinology and Metabolism, Department of Medicine, ${ }^{2}$ Department of Community Health Sciences, \\ ${ }^{3}$ Department of Surgery, ${ }^{4}$ Department of Pathology and Laboratory Medicine, University of Calgary, Calgary, Alberta, \\ Canada, and ${ }^{5}$ Alberta Precision Laboratories, Alberta Health Services, Calgary, Alberta, Canada
}

\author{
Correspondence \\ should be addressed \\ to A A Leung \\ Email \\ aacleung@ucalgary.ca
}

We thank Dr Ebbehøjfor and colleagues (1) for their enthusiasm for our recent epidemiological study on the incidence of pheochromocytoma and paraganglioma (PPGL) in Alberta, Canada (2), along with their interest in our follow-up analysis showing an increased annual incidence of disease with higher altitude from selected studies (3). In their letter, they conducted an updated search of the literature, analyzed the available data according to annual incidence at the time of observation, and demonstrated that the frequency of detected PPGL has also increased over time.

The findings presented by $\mathrm{Dr}$ Ebbehøjfor and colleagues are important contributions that help to advance our understanding of the epidemiology of PPGL. We point out that their interpretation of the data is not fundamentally different than our own. We previously stated that although variations in altitude account for a small degree of the between-study differences observed (a finding that they also corroborate), other factors such as variable disease detection methods, data sources, and study quality are likely more important sources of statistical heterogeneity $(2,3)$. We also acknowledged the apparent rise in PPGL frequency with more recent data and further postulated that it was mediated, at least in part, through similar mechanisms (i.e. increased global awareness of these tumors with improvements in diagnostic practices over time) (2), as others have likewise suggested (4).

The inclusion of more articles by Dr Ebbehøjfor and colleagues in their updated meta-analysis did not change the finding that there is a measurable and statistically significant increase in the incidence of PPGL with higher altitude. We agree that analyzing the data according to the year that the tumors were detected rather than publication year is a better approach. Still, a very large amount of unexplained statistical heterogeneity remained in the updated meta-analysis with $I^{2}$ values exceeding 80-90\% (5), indicating that the time variable accounts for little of the observed differences in PPGL incidence between studies.

Examining ecological and temporal associations is admittedly very complex, particularly with the challenges in accurately quantifying the cumulative exposure to different altitudes over a person's lifetime and in determining whether apparent changes in disease detection over time are actually independent of increased disease awareness, advances in technology, and improved access to care. Ultimately, these meta-analyses (i.e. both ours and theirs) are limited by aggregate study-level data, so ecological fallacies are possible, and therefore, the findings are best interpreted with caution and reserved for hypothesis generation. As the use of individual participant data for a meta-analysis on this subject is unlikely to ever be feasible, the elucidation of risk factors for PPGL remains best pursued by well-conducted epidemiological studies for the time being, and thus far, these have reported small yet significant associations with both time and space $(4,6)$.

Declaration of interest

The authors declare that there is no conflict of interest that could be perceived as prejudicing the impartiality of this reply.

\section{Funding}

This work did not receive any specific grant from any funding agency in the public, commercial, or not-for-profit sector.
(C) 2022 European Society of Endocrinology Printed in Great Britain
Published by Bioscientifica Ltd. 


\section{Author contribution statement}

All authors contributed to the writing of this letter. All authors read and approved the final manuscript for publication.

\section{References}

1 Ebbehoj A, Poulsen P L \& Søndergaard E. Incidence of PPGL according to altitude - Calendar time is of the essence. European Journal of Endocrinology 2022184 L1-L2. (https://doi.org/10.1530/EJE21-0680)

2 Leung AA, Pasieka JL, Hyrcza MD, Pacaud D, Dong Y, Boyd JM, Sadrzadeh H \& Kline GA. Epidemiology of pheochromocytoma and paraganglioma: population-based cohort study. European Journal of Endocrinology 2021184 19-28. (https://doi.org/10.1530/ EJE-20-0628
3 Leung AA, Hyrcza MD, Pasieka JL \& Kline GA. Incidence of pheochromocytoma and paraganglioma varies according to altitude: meta-regression analysis. European Journal of Endocrinology 2021184 L21-L23. (https://doi.org/10.1530/EJE-21-0258)

4 Berends AMA, Buitenwerf E, de Krijger RR, Veeger NJGM, van der Horst-Schrivers ANA, Links TP \& Kerstens MN. Incidence of pheochromocytoma and sympathetic paraganglioma in the Netherlands: a nationwide study and systematic review. European Journal of Internal Medicine 201851 68-73. (https://doi.org/10.1016/j.ejim.2018.01.015)

5 Higgins JP, Thompson SG, Deeks JJ \& Altman DG. Measuring inconsistency in meta-analyses. BMJ 2003327 557-560. (https://doi. org/10.1136/bmj.327.7414.557)

6 Astrom K, Cohen JE, Willett-Brozick JE, Aston CE \& Baysal BE. Altitude is a phenotypic modifier in hereditary paraganglioma type 1 : evidence for an oxygen-sensing defect. Human Genetics 2003113 228-237. (https://doi.org/10.1007/s00439-003-0969-6)

Received 21 October 2021

Accepted 27 October 2021 